\title{
LA EDUCACIÓN CIUDADANA: MARCIAL ANTONIO LÓPEZ, RAMÓN SALAS Y LA PRENSA AFRANCESADA EN LA DIFUSIÓN DE LA DOCTRINA LIBERAL
}

Education for citizenship: How Marcial Antonio López, Ramón Salas and the francophile press helped spread liberal ideas

\author{
MARÍA LUISA SÁNCHEZ-MEJÍA \\ Universidad Complutense de Madrid \\ sanchezmejia@cps.ucm.es
}

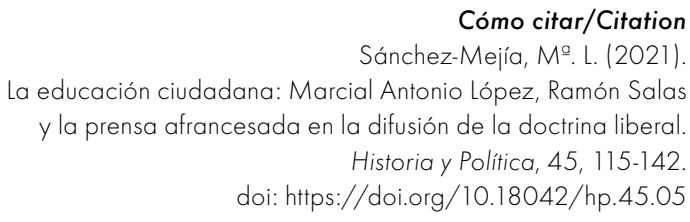

(Recepción: 16/01/2020; evaluación: 08/05/2020; aceptación: 19/09/2020; publicación: 01/06/2021)

\section{Resumen}

Entre 1820 y 1823 hubo un gran afán por difundir y explicar los principios y los mecanismos de los sistemas liberales. El presente artículo se centra en tres de los focos principales que sirvieron a esta tarea educadora y divulgadora: las Observaciones que Marcial Antonio López hizo a su traducción de los textos de Benjamin Constant; las Lecciones de derecho politico para las escuelas de España, de Ramón Salas, y los diccionarios y compendios de teoría liberal de los periódicos afrancesados El Censor y la Miscelánea de Comercio, Politica y Literatura. El liberalismo moderado, 
bien conectado con las ideas liberales europeas, encontró en estas publicaciones un vehículo para la educación ciudadana y un freno para las ideas más radicales.

\section{Palabras clave}

Trienio liberal; educación política; Marcial Antonio López; Ramón Salas; afrancesados.

\section{Abstract}

In the period of 1820-1823, many in Spain showed great interest in spreading and explaining the principles and mechanics of Liberalism. This article focuses on three of the most important instruments which contributed to this educational and divulgatory task: the Observaciones attached by Marcial Antonio López to his translation of texts by Benjamin Constant; the Lecciones de derecho politico para las escuelas de España, by Ramón Salas; and the various dictionaries and compendia of liberal theory published by francophile newspapers El Censor and La Miscelánea de Comercio, Politica y Literatura. Moderate liberals, well-versed in the liberal ideas circulating at the time in Europe, used these publications not only as vehicles for educating the citizenry, but also as a barrier to lock out more radical ideas.

\section{Keywords}

Liberal triennium; political education; Marcial Antonio López; Ramón Salas; francophile journals. 
I. INTRODUCCIÓN. II. CONSTANT Y LÓPEZ. III. LAS LECCIONES DE SALAS. IV. PEDAGOGÍA FRANCESADA. V. EL LABERINTO DE LA IGUALDAD. VI. PUEBLO Y NACIÓN. VII. lOS FRUTOS TARdíOS. Bibliografía. Artículos de prensa.

\section{INTRODUCCIÓN}

«Los españoles — dice Ramón Salas — - hemos vivido en la ignorancia de las verdades que más importan al género humano: ¿y cómo podríamos saberlas cuando no solamente no se nos enseñaban, sino que se nos privaba con el mayor cuidado de todos los medios para adquirirlas?». Las verdades que más importan al género humano son, evidentemente, las relativas al gobierno de una república y a la convivencia entre sus ciudadanos, y Ramón Salas quería contribuir a su difusión por medio de sus Lecciones de derecho público constitucional para las escuelas de España, publicada en 1821, con ese afán pedagógico que caracterizó al Trienio Liberal a la hora de enseñar liberalismo a los españoles.

¿Era quizá esa ignorancia la que había impedido la consolidación de la Constitución gaditana y había facilitado su pronta derogación a manos de un monarca absoluto?

La Constitución de 1812 se había esforzado, sin embargo, en imponer una política educativa que incluyera la enseñanza de la ley constitucional, indicando en el art. 368 «que el plan general de enseñanza será uniforme en todo el reino, debiendo explicarse la Constitución de la Monarquía en todas las Universidades y establecimientos literarios donde se enseñen las ciencias civiles y eclesiásticas». Pero, aunque alguna cátedra se puso en marcha para seguir esta dirección, la vuelta del rey dejó en suspenso tan voluntarioso proyecto, que hubo de retomarse en 1820 . De nuevo se puso en marcha un ambicioso plan de enseńanza por el decreto de 24 de abril de 1820 , en el que se recomendaba a las universidades el restablecimiento de las cátedras creadas en 1814 , se ordenaba que «en todas las escuelas de primeras letras y humanidades del reino se explicara por los maestros la constitución» y se ordenaba incluso a los curas párrocos la explicación de la Constitución al término de la

$1 \quad$ Salas (1982): 5-6. 
misa, bajo amenaza de duras sanciones. Órdenes y recomendaciones que pocas veces se siguieron, que acarrearon censuras y odios a quienes no cumplían y que carecieron no solo de la voluntad de muchos implicados, sino también de fondos y tiempo para que se pudieran implementar. ${ }^{2}$

El esfuerzo de los legisladores evidencia, en cualquier caso, la convicción de que era necesaria una tarea de educación de los ciudadanos en el contenido de la Constitución y, en general, en los principios del gobierno representativo para lograr quizá la suficiente adhesión al sistema liberal que impidiera de nuevo su aniquilación por parte del absolutismo.

Durante los años del Trienio los canales de difusión del liberalismo constitucional fueron muy variados: ediciones de obras de teoría política, traducciones de autores extranjeros, enseñanza oficial en escuelas y universidades, gabinetes de lectura, prensa, actividad de sociedades patrióticas y culturales, tertulias... Con el objetivo añadido de configurar el nuevo poder social: la opinión pública, y servirse de ella para fines partidistas o, al menos, para legitimar propuestas ideológicas ${ }^{3}$.

En este artículo nos detendremos en los tres focos que tuvieron mayor alcance en la difusión de la Constitución y de los principios liberales desde la óptica del liberalismo moderado: a) la traducción de la obra de Benjamin Constant y las Observaciones que su traductor, Marcial Antonio López, añadió a cada capítulo, un contraste no analizado hasta ahora; b) la edición de las Lecciones de derecho constitucional para las escuelas de España, de Ramón Salas, y sus pretensiones de ser un manual para la formación de los ciudadanos, y c) los compendios de teoría liberal publicados por los diarios El Censor y la Miscelánea de Comercio, Política y Literatura, a modo de diccionarios para aclarar y delimitar en la mente de sus lectores los conceptos principales.

\section{CONSTANT Y LÓPEZ}

Pocos meses después del pronunciamiento de Riego ${ }^{4}$, se publica en Madrid, en la imprenta de la Compañía y en tres volúmenes, una obra titulada Curso de política constitucional, "escrito por Mr. Benjamin Constant, traducido libremente al español por Marcial Antonio López»s, diputado en las

Fernández Alles (2012); Peset (1998), y Sánchez Agesta (1962).

Morange (2004).

El Universal anuncia la publicación de la obra en su número de 20 de junio de 1820.

5 Referencia completa: Constant, B., Curso de política constitucional (1820), Madrid, Imprenta de la Compañía. Para el contenido específico del Curso y la procedencia de 
primeras Cortes del Trienio. Constant había publicado su Cours dos años antes, cuando quiso emprender una nueva etapa política como diputado en la Asamblea francesa. Pretendía defenderse de quienes le acusaban de veleidad al haberse puesto al servicio de Bonaparte en los Cien Días, habiendo sido previamente su enemigo. Pretendía mostrar a través de sus obras que siempre había profesado las mismas ideas de libertad individual y de representación política tanto bajo la república como en los Cien Días o en la monarquía restaurada. «He pensado — dice - que unas obras destinadas a reivindicar nuestras libertades, apoyándolas en principios claros, aplicables e independientes de las formas [políticas] [...] servirán a la causa a la que he consagrado mi vida desde hace muchos años» ${ }^{6}$,

La oportunidad de la traducción de López, recién reestablecida la Constitución de 1812, y la celebridad de la que gozaba ya Constant en España hicieron que el Curso tuviera una amplia repercusión en los círculos liberales, hasta el punto de que se convirtió en el libro de texto oficial de la Cátedra de Derecho público y Constitución en la recién creada Universidad Central7. Martínez Marina, Ramón Salas y Alcalá Galiano bebieron de las aguas constantianas y los periódicos afrancesados le tuvieron también por guía y referencia en sus artículos sobre conceptos liberales, como ya veremos. ${ }^{8}$

El Curso de Constant-López era verdaderamente libre en su contenido y en su traducción. No se correspondía con ninguna obra completa del autor suizo-francés; era el resultado de ensamblar textos de aquí y de allá9 para responder a lo que López pretendía que fueran unas lecciones de liberalismo para los españoles que se estrenaban en la teoría y práctica de esa

los textos, Sánchez-Mejía, M. L. 1998. El Cours original, compuesto por el propio Constant con algunas de sus obras ya publicadas y nuevos comentarios y añadidos, se había publicado por primera vez en París, en 1818, en la editorial Plancher, con el largo título de Collection complète des ouvrages publiés sur le Gouvernement représentatif et la Constitution actuelle de la France, formant une espèce de Cours de politique constitutionnelle. Hubo nuevas ediciones en 1836, 1861 y 1872, variando siempre la selección de obras incluidas. La edición en español de Marcial Antonio López se publicó también en Burdeos en 1821 y 1823, debido al interés de los exilados españoles. En 1825 aparece una nueva traducción en París y México, más fiel al original en su selección de textos, firmada por D. J. C. Pagès, intérprete real, que no hay que confundir con Jean-Paul Pagès, editor del Cours en francés de 1836.

6 Constant (1818), p. III.

7 Así se establece en el Reglamento General de Instrucción Pública, elaborado por las Cortes el 10 de junio de 1821: Sánchez de la Campa (1871).

8 Sánchez-Mejía (1998).

$9 \quad I d$. 
doctrina. En una carta dirigida al autor y publicada por el propio López al final de su Curso aseguraba que había buscado en Constant «al Mentor de todos nosotros" y "al más amante de las instituciones liberales» por "haber dado las pruebas más grandes de amor a su patria, a la independencia del hombre y a su dignidad», virtudes que el diputado español consideraba adecuadas al momento que vivía España «al desasirse de las cadenas con que la tenía agobiada el despotismo». ${ }^{10}$

Pero López no se limita a componer el Curso por su cuenta, sino que ańade unas Observaciones de su propia mano al final de cada capítulo para glosar los artículos o los contenidos de la Constitución de Cádiz que mejor se relacionan con los textos de Constant. Estos comentarios, que son los que nos interesan aquí porque reflejan el pensamiento de Marcial Antonio López, convierten el Curso en una obra de dos autores que no siempre están de acuerdo en el contenido y que van discutiendo principios e instituciones en un ejercicio que genera a veces una cierta confusión en el lector, pero que permite, sin duda y si así se desea, una reflexión autónoma sobre lo que mejor conviene a España en esas circunstancias.

Cuatro son las cuestiones principales sobre las que discrepa López respecto a Benjamin Constant, si bien muestra su acuerdo en una buena parte de las propuestas de este. Estas discrepancias ilustran muy bien la educación liberal que se quería ofrecer a los lectores para mantenerse siempre dentro del marco constitucional.

En primer lugar, Constant coloca la soberanía en el pueblo, un principio que, según él, «no puede ser contestado». Los comentarios de López en cambio otorgan la soberanía a la nación, de acuerdo con el art. 3 de la Constitución, y la potestad de hacer las leyes a las Cortes con el rey. Los argumentos para este cambio nos llevan a la segunda controversia con Constant, que alcanza esta vez todo el trasfondo tanto de la teoría liberal constantiana como de la Constitución de 1812: López considera que la soberanía nacional procede «del derecho primitivo de las naciones», y en la historia de España se puede encontrar «desde que se sancionaron los primeros códigos hasta que los fatales sucesos de la batalla de los campos de Villalar sepultaron con los héroes espańoles el acendrado patriotismo y los nobles sentimientos", y la facultad de darse leyes «fue degenerando por la unión de los Reinos», derechos felizmente restablecidos hoy con la Constitución de Cádiz ${ }^{11}$.

\footnotetext{
10 Constant-López (1820), t. III: 245-250. Esta obra se citará con el nombre de ambos autores, ya que las alusiones son fundamentalmente a las Observaciones que Marcial Antonio López fue añadiendo a los textos de Constant.

11 Constant-López (1820), t. I: 25-28.
} 
En este capítulo I del Curso, López retoma lo ya mencionado en el «Discurso preliminar» de la obra, y que va a repetir una y otra vez a lo largo de sus Observaciones: los legisladores de Cádiz buscaron, y hallaron, los principios y las instituciones «en las antiguas leyes fundamentales de Aragón, Navarra y Castilla [...] y solo alteraron lo que no era compatible con los principios del mundo actual. [...] Pero en lo sustancial no hicieron sino renovar aquellas reglas que en las épocas de gloria nos rigieron ${ }^{\prime 2}$. Esta pretendida filiación histórica de la Constitución de 1812 fue uno de los ejes vertebradores de los debates gaditanos y generó una discusión que se trasladó a los años del Trienio, y sirvió, entre otros argumentos, para distinguir a los seguidores más fieles del texto, como Marcial Antonio López, de otros liberales con ideas más autónomas como Salas, Lista o Burgos, como veremos más adelante ${ }^{13}$. Esta defensa de la Constitución como recuperación de las antiguas leyes medievales contrasta, evidentemente, con la percepción que tiene Constant del régimen liberal como la etapa histórica llamada a suceder a la sociedad nobiliaria del Antiguo Régimen. Una visión de la historia en etapas que entrańa una idea de progreso, de movimiento hacia una meta, y que está muy alejada de esa visión en cierto modo cíclica que señala López.

La elaboración del mito medieval como origen de las libertades españolas por los últimos ilustrados y los liberales gaditanos ha sido debatido en muchas ocasiones ${ }^{14} \mathrm{y}$ no es nuestro objetivo volver sobre la cuestión, más allá de recordar que incluía el temor que suscitaba una revolución que, al igual que la francesa, trajera la violencia y la anarquía social y política. La idea de continuidad debía conjurar este peligro, y por ello el mito sigue presente en los años del Trienio entre los más fieles a la Constitución y nos permite comprender las cautelas que los liberales toman frente a ciertas doctrinas liberales europeas.

Sin negar la validez de estos argumentos, es preciso señalar también que había una cierta idea de ruptura en esa proyección del continuum histórico. Entre la Edad Media y el presente los cuatro siglos de gloria imperial española desparecen del relato. El absolutismo de Austrias y de Borbones no tiene cabida, no se puede reivindicar, y por eso la época feliz se acaba en los campos de Villalar. ¿Época feliz o punto de apoyo para el gran salto? Como ya explicó Hannah Arendt hace muchos años, no puede haber saltos en el vacío y todos los regímenes, y especialmente todas las revoluciones, buscan un antecedente que puedan enseñar para aplacar su miedo a la novedad, a la incertidumbre del futuro. La Revolución francesa quiso encontrarlo en la Antigüedad

12 Ibid.: XVII-XIX.

13 Sánchez-Mejía (1998).

14 Véase, entre otros muchos: Torrecilla (2016) y Álvarez Alonso (2000). 
grecorromana, y la revolución que preparaban las Cortes de Cádiz lo buscó en el periodo medieval de los reinos peninsulares. Y el Trienio heredó todo el paquete: negar cualquier afán revolucionario $y$, a la vez, encontrar en las antiguas monarquías la justificación para las novedades. Esta mezcla de continuidad pretendida y de aspiración transformadora se va a extender a buena parte del siglo XIX $^{15}$ y está en el origen de la búsqueda de la autenticidad española que tantas letras va a dar a la imprenta hasta bien entrado el siglo xx.

Esta tensión entre continuidad y ruptura se pone varias veces en evidencia en la tercera diferencia o discrepancia importante entre Constant y López: el mayor poder a las asambleas representativas con merma de los poderes del rey y de la nobleza. Constant, crítico de la voluntad general roussoniana, propone que el rey, en una monarquía constitucional, tenga capacidad para disolver las asambleas legislativas y evitar así que acumulen un poder omnímodo. Contempla además la necesidad de una cámara de representación nobiliaria que sirva para la estabilización del sistema y no deje a la representación popular en solitario para hacer y deshacer a su antojo. Protagonismo del rey y la nobleza que habían estado presentes también en las «antiguas leyes españolas» y que deberían haber complacido a Marcial Antonio López. Sin embargo, el diputado espańol se opone tajantemente a otorgar al monarca esa capacidad de disolución de las asambleas, amplía los poderes de estas para intervenir en las declaraciones de guerra y en los tratados de paz — algo que Constant rechaza explícitamente- y no ve ningún interés ni necesidad en dar protagonismo a la nobleza. Siguiendo la Constitución del 12, defiende la existencia de un Consejo de Estado donde la presencia de los nobles es muy limitada y donde se da cabida, en cambio, a los representantes de las profesiones llamadas liberales - las capacidades-, mucho más propio de las sociedades post Antiguo Régimen. Y cuando encuentra elementos de esas veneradas leyes antiguas que casan mal con los valores verdaderamente modernos, como las confiscaciones de bienes, López no duda en rechazarlos y afirma que «en la época presente, en que la naturaleza ha recobrado sus derechos por un efecto preciso de la ilustración, no deben ya ocuparnos ${ }^{16}$.

Solo hay una cuestión en que el desacuerdo con Constant y, a la vez, la fidelidad a la tradición no deja lugar a dudas: la religión. Constant, evidentemente, defiende la libertad de cultos, uno de los fundamentos del pensamiento liberal. López declara en cambio que, en este punto, no va a seguir la doctrina de su admirado mentor, puesto que la Constitución no reconoce esa libertad. Sabe que Constant «pone la libertad religiosa como el tercero de los

15 Torrecilla (2016).

16 Constant-López (1820), t.II: 166. 
derechos individuales del hombre», y que el establecimiento de la libertad de cultos «sin restricción y sin privilegios» es para este autor «la sola medida razonable y conforme a los verdaderos principios» ${ }^{17}$. Ańade incluso que él hubiera querido dar al pie de la letra y sin omisiones «todas las doctrinas de este sabio escritor», pero se lo impide la obligación de ser fiel a las leyes del Estado, razón por la cual suprime todo el capítulo y lo sustituye por sus propias reflexiones en esta materia. Incluso cuando en el tomo III del Curso incluye una traducción de la conocida conferencia de Constant «De la libertad de los antiguos comparada con la de los modernos» y enumera los derechos de los individuos, López suprime simplemente la frase que reconoce el derecho de reunirse con otros individuos para profesar el culto que él y sus asociados prefieran ${ }^{18}$.

El Curso de politica constitucional, que tanta influencia tuvo en los ańos del Trienio, mezclaba así las ideas del liberalismo individualista de Constant con las más nacionales y quizá más ingenuas de López, trasmitiendo al lector, al educando liberal, un mensaje un tanto confuso.

Marcial Antonio López, de formación ilustrada y contertulio de Ramón Salas, Meléndez Valdés, y Quintana entre otros, obtuvo un inmediato renombre político al inicio del Trienio cuando fue nombrado secretario de las Cortes a las que había llegado como diputado por Aragón ${ }^{19}$. Aunque más tarde los radicales criticarían su moderación, en sus Observaciones a los textos de Constant se muestra muy confiado en los ciudadanos y su capacidad de autogobierno frente a los poderes que Constant quiere para el rey constitucional y que López prefiere ver muy recortados. Los escasos datos que tenemos de su trayectoria anterior al Trienio no nos permiten saber si era partidario de un ejecutivo fuerte o más bien de un modelo más francés con más poder para la asamblea ${ }^{20}$, pero muestra en todo caso poco apego al rey y a la nobleza y gran fidelidad a la Constitución de 1812, en la que ve una y otra vez esa idea de pacto entre el monarca y su pueblo, de tanto recorrido en la filosofía política española ${ }^{21}$, y que López utiliza para exaltar la segunda parte del binomio: el pueblo, aunque en este caso sea la nación.

Menos titubeos hay en torno a la cuestión religiosa, como ya se ha apuntado. Sin embargo, y pese a la férrea defensa de la confesionalidad de

\footnotetext{
Ibid.: 107.

Constant-López (1820), t. III: 56.

19 «Marcial Antonio López Quílez», biografía escrita por María Luisa Sánchez-Mejía. Web del Diccionario biográfico español de la Real Academia de la Historia. Consultado el 14 de enero de 2020 (https://bit.ly/3qqkQts).

20 Varela Suanzes (1998): 86-89; Bustos (2015): 59-61.

21 Álvarez Alonso (2000).
} 
López, nunca cierra la puerta a un cambio futuro. En la línea de algunos legisladores gaditanos, López alude a que "podría causarnos en la actualidad (cursiva mía), muy grandes males» y acepta que la libertad religiosa es buena donde hay ya personas de otras religiones y el Estado deba mirar por el bienestar de todos, que no es el caso de España ${ }^{22}$. Parece inclinarse así por esa distinción entre intolerancia teológica e intolerancia civil, adoptada por algunos legisladores gaditanos ${ }^{23}$, que no cierra la puerta a una modificación en el futuro. En cualquier caso, la cuestión religiosa no invalida el conjunto del primer liberalismo español ni el concepto de nación española, como a veces se remarca ${ }^{24}$. Además de los ecos burkeanos de la identificación entre nación y religión, hay que recordar que la Constitución noruega de 1814 también se asociaba la nación con la confesionalidad luterana, ejemplos de la persistencia de huellas confesionales en las primeras etapas de las constituciones liberales.

\section{LAS LECCIONES DE SALAS}

Aunque la historiografía jurídica considera las Lecciones de Salas como «la obra fundadora de la ciencia española del Derecho constitucional $»^{25}$, el autor la tenía por una obra apresurada, impulsada por la urgencia de suplir la falta de textos sobre esta materia en los inicios del Trienio y ofrecer la educación constitucional que las circunstancias requerían ${ }^{26}$ porque «nada corre más prisa que enseñar al pueblo español sus derechos y sus verdaderos intereses ${ }^{27}$. Las Lecciones contribuyeron decisivamente a la celebridad de Salas, antiguo profesor de la Universidad de Salamanca, perseguido por la Inquisición durante el reinado de Carlos IV y condenado a quince años de confinamiento. Aun sin datos precisos sobre sus etapas posteriores, parece que fue afrancesado y que ejerció como abogado en Madrid. Traductor e introductor de Bentham en España, sus comentarios a los Tratados de legislación civil y penal del utilitarista inglés y al Tratado de los delitos y las penas de Beccaria hicieron también de él lo que podemos llamar «un clásico político» ${ }^{28}$.

\footnotetext{
Constant-López (1820), t. II: 108-110.

3 La Parra (2014).

Llorente (2006).

Fernández Sarasola (2011): 644.

García Costa (2005): 37.

Salas (1982): 21.

28 Bermejo Cabrero (1982) y https://bit.ly/2LU9mPP.
} 
Las Lecciones, divididas en dos partes, pretenden ser una exposición de los principios generales de lo que él denomina «la ciencia social», y confrontar después con ellos «los contenidos de nuestra constitución política». Las Lecciones se centran en tres cuestiones principales: los derechos y las libertades, el régimen político y la división de poderes, tres elementos fundamentales del liberalismo que los ciudadanos deben aprender por encima de toda la trama de artículos y reglamentos que contiene el texto de 1812, pues considera que toda constitución debe retenerse fácilmente en la memoria ${ }^{29}$.

Y lo primero que hay que conocer son los derechos: «Una buena constitución política debe contener una declaración de los derechos que los ciudadanos se han querido reservar, y a que no fue su intención renunciar al formar una sociedad política, y señalar el modo y condiciones de su asociación $»^{30}$. A pesar de que Salas es el traductor e introductor de Bentham en España ${ }^{31}$, no coincide con él en el carácter legal y no natural de los derechos en su origen. $\mathrm{Al}$ igual que Rousseau o que Mably — a Hobbes y a Locke no los mencionalos derechos son anteriores a la sociedad y la finalidad de esta es protegerlos y garantizarlos, aunque eso no le impide — situándose ahora más cerca de Bentham - afirmar que «los hombres no nacen con derechos iguales ni desiguales: los derechos son criatura de la ley y no existen sin ella ${ }^{32}$.

A la desigualdad natural, en capacidades y habilidades, se suma la desigualdad producida por malas leyes que no saben limitar la ambición, también natural pero comunitariamente nociva, de quienes acumulan riquezas o privilegios. Pero la igualdad ¿̇es posible? La igualdad de derechos es asequible y fácil de establecer, aboliendo los privilegios. La igualdad de riquezas es, en cambio, imposible «si se habla de una igualdad absoluta y permanente», precisamente porque la desigualdad está conectada con las capacidades naturales, «pero las leyes pueden minorar mucho aun esta especie de desigualdad, estorbando el estanco de las riquezas en pocas manos, permitiendo que circulen libremente, protegiendo la industria y dando toda la latitud posible a la acción del interés individual ${ }^{33}$, a lo que se ha de ańadir la prohibición de la facultad de testar. No debe sin embargo la ley atentar en nada a la legítima propiedad, «el más santo de todos los derechos del hombre, el fundamento necesario de toda asociación política ${ }^{34}$.

\footnotetext{
29 Fernández Allés (2012): 312.

30 Salas (1982): 33.

31 Para la recepción de Bentham en España y la tarea de traducción que hizo Salas: Sánchez García (2007).

32 Salas (1982): 44.

33 Ibid.: 45.

34 Id.
} 
Tampoco la libertad absoluta es posible, pues dañaría la felicidad común, que debe ser el objetivo último de toda asociación humana. La utilidad del conjunto es la medida para el ejercicio de la libertad y para su limitación. Este ejercicio debe incluir la libertad individual, es decir, la seguridad personal, la ausencia de arbitrariedad y las garantías jurídicas, la libertad de imprenta y la libertad de cultos.

La libertad de imprenta es para Salas la más importante de todas porque es «la salvaguardia, la centinela y la protectora de todas las otras libertades, tanto que es posible asegurar que mientras un pueblo conserve intacta la libertad de imprenta, no es posible reducirlo a esclavitud $\aleph^{35}$. La libertad de imprenta va asociada, por un lado, a la instrucción pública para crear lectores entendidos y responsables y, por otro, a la formación de la opinión (pública), imprescindible en un sistema liberal, como luego veremos. Salas hace gala en este tema de una extrema ortodoxia liberal, aceptando la libertad de expresión incluso sobre lo que se pueda considerar contrario a la moral, debido al relativismo de todos los valores, o contrario a la religión, por la diversidad de opiniones religiosas. La solución es siempre más libertad, más opiniones contrapuestas, más posibilidad de defender todas las ideas. Tan solo los delitos de injurias y calumnias deben ser perseguidos, y no con leyes especiales, sino como delitos sin más. Hay una cierta ingenuidad de liberal recién estrenado en la confianza en que la prensa expresará la voz de pueblo y en que los gobernantes serán guiados así en la razón y en la justicia, pero importa destacar que en este primer momento sienta ya las bases claras de un derecho que, siempre sometido a debates, va a marcar todo el siglo.

Esta decidida defensa de la libertad de expresión, contenida en las lecciones VIII y IX, contrasta sin embargo con la retirada poco airosa que muestra frente a la cuestión de la libertad de cultos en la lección siguiente, titulada "Libertad de conciencia o de religión", apenas dos párrafos para decir que su fundamento es de sobra conocido y que los lectores pueden acudir a cualquiera de los libros dedicados a esta materia para conocer sus principios o mirar el ejemplo de los pueblos modernos y observar cuál es su conducta ${ }^{36}$. Toda la modernidad que reflejan las Lecciones queda desmentida en este capítulo. Se adivina la complejidad política que subyace a este silencio y, quizá, el pragmatismo que le lleva a callar a cambio de difundir el resto de sus opiniones políticas.

Salas no menciona la nación a la hora de fijar el origen del poder político: solo el pueblo es soberano de manera irrenunciable; solo delega el ejercicio del

35 Ibid.: 64. 
poder, si bien asegura que los Gobiernos nacionales no tienen otros intereses que los de la nación, asimilando los dos conceptos, pueblo y nación. El gobierno representativo es el más adecuado en el grado de civilización en que nos encontramos, el tercero, "porque es el que deja más libertad a los ciudadanos, conserva mejor entre ellos la igualdad civil y les da más probabilidades de felicidad $\aleph^{37}$.

Un sistema electoral indirecto, pero con pocas exclusiones —entre ellas las de los empleados públicos-, y una eficaz división de poderes configuran en las Lecciones de Salas el funcionamiento del modelo liberal, con la novedad de dos poderes añadidos a la tríada habitual: el poder conservador, con atribuciones a medias entre un senado y un tribunal constitucional, y un poder regulador similar al de un monarca neutro que armonice a los otros poderes.

Esta es la receta que puede "conservarse en la memoria» y enseñarse en todas las escuelas de España, como quería Salas: soberanía popular, igualdad ante la ley, libertad individual, libertad de imprenta, gobierno representativo y división de poderes.

Sin veleidades historicistas ni lealtades a oscuras tradiciones nacionales, las Lecciones emparentan con el primer liberalismo europeo mucho mejor que las componendas de Marcial Antonio López. La influencia de Bentham — con el que a menudo está en desacuerdo-, de Sieyès, de Destutt de Tracy o de Constant es clara ${ }^{38}$, tanto en los derechos y libertades como en el diseño constitucional. Sin reverencias a la Constitución del 12, pero sin confrontarla, Salas ofrece a sus lectores los elementos imprescindibles para que juzguen por sí mismos, para que lean el articulado de Cádiz con conocimiento de causa y para que empiecen a convertirse en ciudadanos capaces de tomar sus propias decisiones políticas.

\section{PEDAGOGÍA AFRANCESADA}

A pesar de la buena recepción, entusiasta casi, de traducciones y compendios de derecho constitucional y sobre los principios políticos del nuevo régimen, la gran difusión del liberalismo de corte europeo vino de la mano de la prensa moderada, más asequible, más atractiva y más fácil de asimilar que los tratados jurídicos por parte de quienes no eran eruditos ni especialistas en la filosofía de las sociedades. Los periódicos se entregaron, además, de lleno a esta misión pedagógica, comprendiendo la importancia de mostrar con

37 Ibid.: 93.

38 Fernández Sarasola (2011): 646-647. 
claridad a sus lectores el abecé del liberalismo, en la esperanza de que esta formación fuera una barrera frente a las amenazas del absolutismo.

La prensa publicada por antiguos afrancesados fue especialmente activa en esta tarea, y en ella destacan sobre todo El Censor y la Miscelánea de Comercio, Politica y Literatura $^{39}$. Sus editores, alejados del Gobierno por su pasado, con mayor contacto con el extranjero por su experiencia en el exilio y menos beligerantes en los asuntos del día al inicio de la etapa liberal, consagraron la parte más importante de sus páginas a una consciente labor de difusión de los principios liberales y de matización o contención de las interpretaciones más extremas de los mismos. El entusiasmo y la identificación con el régimen que se acababa de implantar fue más patente al inicio del Trienio; los conflictos y la radicalización posterior enfriaron el apoyo inicial y acabaron con ambas publicaciones antes de que se truncara el proyecto político implantado en 1820.

El Censor fue una iniciativa de «sectores vinculados al liberalismo francés», quizá ante la imposibilidad de expresarse libremente en Francia, como les sucedía a los publicistas vinculados a La Minerve. Lanzar un periódico en España era un modo de seguir defendiendo las ideas liberales y continuar la lucha ${ }^{40}$. López Tábar apunta también a "diferentes intereses franceses, tanto económicos como políticos [...] [deseosos de] introducir en España el pensamiento doctrinario»" ${ }^{41}$. Contó con nombres importantes entre sus colaboradores, especialmente Alberto Lista, que firmó muchos artículos políticos además de los literarios $^{42}$, pero también Sebastián Miñano, encargado de la parte satírica, o José Gómez Hermosilla, igualmente articulista político.

La Miscelánea fue el empeño personal de Javier de Burgos, literato y periodista que había ocupado cargos de menor relevancia en Andalucía durante el

39 El periódico fue creado con el título de Miscelánea de Comercio, Arte y Literatura en 1818, pasando a denominarse Miscelánea de Comercio, Política y Literatura el 1 de junio de 1820 .

40 Una carta desde París de Miñano a Reinoso, que participó en el proyecto inicial, le aseguraba que tendría como colaboradores «al abate Pradt, Benjamin Constant, Say, Manuel y algunos otros» (Morange, 2019: 31-32). Claude Morange nos ofrece noticia detallada de los orígenes del periódico y de su posterior desarrollo y contenido en una rigurosa y exhaustiva investigación reseñada en el apartado bibliográfico de este artículo.

41 López Tabar (2001).

42 Juretschke (1951). Para un análisis del pensamiento político de Alberto Lista, reflejado a menudo en las páginas de El Censor: González Manso (2011); Carbajosa Aguilera (2016). 
reinado de José I. Fundada como publicación económica y literaria, en marzo de 1820 se convirtió en periódico político y se benefició de la falta de competencia en los meses posteriores al pronunciamiento de Riego ${ }^{43}$. Quiso jugar un importante papel en la formación de la opinión pública, pero el entusiasmo inicial se fue enfriando por la radicalización del ambiente político y se cerró en septiembre de 1821. Utilitarista, seguidor de Bentham y de Destutt de Tracy, siempre consideró la conveniencia pública como la base del pacto social.

No es intención de este artículo analizar el contenido ideológico y político de la prensa afrancesada, bien estudiada desde hace ya bastantes años por historiadores como Antonio Elorza, Jan Juretschke, Claude Morange o los ya citados López Tabar o Morán Ortí. Se trata únicamente de resaltar su afán pedagógico, de difusión de las principales ideas liberales. Un afán no exento de contradicción, por cuanto se propone instruir a los ciudadanos en los rudimentos del sistema liberal, para ir luego enfatizando que solo los más versados y capaces son los llamados a la toma de decisiones y que cada uno debe seguir ocupando el puesto que le corresponde en la sociedad, como veremos. Pero,aun así, o precisamente porque no debe revolucionarse el orden social, un sistema representativo exige votantes para elegir a esos instruidos representantes y para vigilarlos y sostener las libertades, evitando que instituciones - como la Corona - o intereses parciales amenacen el mantenimiento de la Constitución. Un cierto temor parece inspirar con frecuencia los artículos de El Censor y la Miscelánea, con 1814 y la vuelta del absolutismo en la memoria, y siempre con los desmanes revolucionarios franceses en el horizonte.

Esta desconfianza hace que resulte urgente crear un "espíritu público» que sea lo contrario del «espíritu de partido». Este último no reconoce más patria que su propia facción ni otros ciudadanos que los que profesan unas mismas opiniones, mientras que el primero es «el apego o afición que toma la porción ilustrada del pueblo en el sistema general de su gobierno, y en los actos particulares de la administración $»^{44}$. Es, en opinión de la Miscelánea, "un egoísmo en grande, generalizado, útil e indefinidamente comunicable» ${ }^{45}$. Es necesario, pues, que se vaya creando ese «apego» a los asuntos públicos, en primer lugar a través de la instrucción: la difusión de las doctrinas políticas "presentadas continuamente al pueblo con claridad, con método y con prudencia, le sacarán poco a poco de la ignorancia en la que yace», y aunque

\footnotetext{
43 Morán Ortí (1989): 265 y ss.

44 El Censor, n. ${ }^{\circ}$ 13, 28-10-1820: 66. En adelante se citará abreviado como E.C. Se ha modernizado la ortografía y la puntuación en todas las citas de las publicaciones periódicas.

45 Miscelánea de Comercio, n. ${ }^{\circ} 84,1820$. En adelante se citará abreviado como $M . C$.
} 
propone, con bastante ingenuidad, «que los párrocos y todos aquellos dedicados a la enseñanza pública [...] se dediquen a las ciencias morales y políticas, de que en breve se irán dando a la luz algunas obras clásicas», a esta instrucción contribuirán especialmente «los periódicos y los papeles volantes, que si bien no pueden proporcionar una instrucción fundamental, excitan el deseo de adquirirla, propagan y hacen comunes las luces» ${ }^{46}$, porque "es difícil más no imposible poner al alcance de todos, los motivos que prueban que hay un interés general» en la legislación o en las medidas que se adoptan ${ }^{47}$. De ahí la importancia de la definición de los conceptos políticos más importantes como primer paso hacia la adquisición de esas luces.

La Miscelánea ofrece un Diccionario político y moral "para definir las voces capitales de la ciencia social, y trabajar por que se determine su acepción ${ }^{48}$, "porque sabrá las cosas mismas, decía Platón, el que llega a conocer sus nombres ${ }^{49}$. Y evitar así «una de las principales causas de nuestros errores, y acaso la única, [como es] el abuso, o lo que es lo mismo, la mala inteligencia de las palabras que empleamos para expresar nuestras ideas ${ }^{50}$. Y con este propósito ambos periódicos ofrecen la definición y buen entendimiento de los conceptos básicos del liberalismo: constitución, libertad, igualdad, soberanía, ciudadano, nación, pueblo..., así como los elementos propios del gobierno representativo: cámaras representativas, elecciones populares, poder del rey, poder judicial... Y a través de estas precisiones se puede ver el modelo liberal que desean trasladar a sus lectores de manera mucho más nítida que en los artículos sobre la actualidad política.

La primera exposición teórica que llama la atención es, lógicamente, la libertad. Concepto que precisa de muchas distinciones y muchos matices, que los redactores no rehúyen en ningún caso. La influencia de Bentham lleva a rechazar la idea de una libertad natural, cuya existencia «es una de aquellas verdades cuya convicción es más bien obra del sentimiento que del raciocinio $»^{51}$, y solo se admite como libertad natural lo contrario a la esclavitud ${ }^{52}$. «El

46 «Sobre el modo de instruir al pueblo en las doctrinas políticas», M. C., n. ${ }^{\circ} 111,19-6-$ 1820 .

47 «Sobre la instrucción del pueblo en las doctrinas constitucionales», $M$. C., n.o 179, 26-8-1820

48 «Los periódicos se van multiplicando [...]», M. C., n. ${ }^{\circ} 84,12-5-1820$.

49 «Sobre la instrucción del pueblo en las doctrinas constitucionales», $M$. C., n.o 179 , 26-8-1820

50 «Libertad, Igualdad. Acepción legal de estas voces», E. C., n. ${ }^{\circ}$ 58, 8-9-1821.

51 «De la libertad social», $M$. . C., n. ${ }^{\circ} 313,6-1-1821$.

52 «Libertad, Igualdad. Acepción legal de estas voces», E. C., n. ${ }^{\circ}$ 58, 8-9-1821. 
hombre no nace libre en ninguno de los sentidos que puede tener la palabra libertad. [...] El hombre nace en un estado de esclavitud natural, moral, legal y política [...]. No hay derechos anteriores a la institución de los gobiernos ${ }^{53}$. A partir de ahí se vincula toda libertad a la sociedad y a las leyes: «La libertad civil no es otra cosa que una esclavitud voluntaria, es decir, la dichosa precisión en que el hombre se constituye el día que se reúne con sus semejantes» ${ }^{54}$. Como se ve, el rechazo de la libertad natural no implica rechazar también la teoría del contrato social, que suele ir asociada a la anterior, pero sobre esta idea volveremos un poco más adelante. En lo que hay acuerdo en los periódicos es en la distinción entre la libertad individual, denominada civil, y la libertad política. La influencia de Constant es evidente también aquí, debido quizá a la temprana aparición de la traducción de López, pero más aun al tratarse de la prensa afrancesada, que sigue las andanzas del autor franco-suizo y recoge con frecuencia sus conferencias y sus intervenciones en la Asamblea francesa. De hecho, la famosa conferencia «De la libertad de los antiguos comparada con la de los modernos» aparece recogida y traducida en los números 117, 120 y 124 de la Miscelánea ${ }^{55}$ y a la que vuelve en el número $313^{56}$ al enumerar todos los derechos privados, empezando por la protección y el uso y abuso de la propiedad. De manera que queda muy claro que «la libertad natural consiste en no ser esclavos, la libertad civil consiste en ser regidos por leyes [...]. Y la libertad política que consiste en concurrir directa o indirectamente $[\ldots]$ a la formación de la ley,s7.

Sin embargo, la prensa afrancesada, siempre moderada, deja muy claro que la libertad tiene sus límites y que hay que poner mucho cuidado en que no se pretenda abusar de ella. La Miscelánea rechaza las expresiones «el pueblo quiere, el pueblo exige»: «El pueblo no puede querer sino lo que le conviene, y no puede convenirle más que la justicia desapasionada, la ilustración enérgica, la moderación generosa» (n..$\left.^{\circ} 84\right)$. Y El Censor apela a leyes no escritas que deben poner freno también a una mala interpretación de la libertad. En su artículo dedicado al concepto de libertad, aparecido en el número 58 ya citado anteriormente, rechaza incluso la comedida definición de Montesquieu de que la libertad consiste en poder hacer lo que las leyes no prohíben, para

53 «Libertad, Igualdad. Acepción legal de estas voces. Concluye el artículo del número anterior", E. C., n. ${ }^{\circ}$ 59, 15-9-1821.

54 «Libertad, Igualdad. Acepción legal de estas voces», E. C., n. ${ }^{\circ} 58,8-9-1821$.

55 "De la libertad de los antiguos comparada con la de los modernos», $M$. C., n. ${ }^{\text {os }} 117$, de 25-6-1820, 120, de 28-6-1820, y 124, de 2-7-1820.

56 «De la libertad social», M. C., n. ${ }^{\circ} 313,6-1-1821$.

57 «Libertad, Igualdad. Acepción legal de estas voces», E, C., n.o 58, 8-9-1821: 254-255. 
recordar que hay otras leyes que es preciso obedecer: las de la buena crianza, las reglas generales de la conducta, las obligaciones morales y de pura civilidad que imponen las relaciones sociales y de las que no nos exime la Constitución, como son la obediencia a nuestros padres y la que debe la mujer al marido. Y no solo debemos abstenernos de lo que perjudique a los demás, sino también de lo que nos perjudique a nosotros mismos, como satisfacer nuestras pasiones a costa de nuestra salud.

Hay, lógicamente, una especial atención a la libertad de imprenta, uno de los grandes combates de la prensa afrancesada ${ }^{58}$, no solo como garantía de la libertad política, sino como vehículo de "espíritu público», esa opinión que circula de abajo a arriba y de arriba abajo, según El Censor:

Hay muchos, que por escasez de luces o por falta de educación, solo se puede decir que tienen sensaciones, pero no que puedan formar opinión, porque ésta solo la forman los hombres instruídos, desde los cuales desciende a todas las clases de la sociedad. Verdad es que las clases más necesitadas... son las primeras que sienten los males... y se quejan de ellos. Mas como sus lamentos se comunican a las otras clases que de ordinariamente dependen, y desde ellas a las más ricas y poderosas, éstas o bien influyen rectamente con la autoridad para su remedio, o bien indirectamente por medio de los papeles públicos (...) para que publicándolos [los males] por medio de la imprenta, se difundan y circule la necesidad del remedio ${ }^{59}$.

\section{En definitiva:}

Toda ley o reglamento que se dirija a prevenir los abusos de la prensa es un reglamento liberticida, el cual acabará tarde o temprano por convertir en arma de la tiranía este magnífico baluarte de la libertad nacional. [...]. Téngase un buen código penal que cierre las puertas a la arbitrariedad y al capricho, y castíguense los delitos que se hubieren cometido ya, mas no los que solo se hubiese pensado cometer ${ }^{60}$.

La diversidad de intereses que manifiestan los partidos políticos, sobre los que luego volveremos, convierten a la prensa para estos primeros liberales en el único cauce por donde circula la verdadera opinión pública, que no entiende de facciones políticas y que manifiesta una unidad de acción que no pueden

\footnotetext{
58 Morange (1990).

59 «Sobre la mayoría de la opinión, y modo con que se forma», E. C., n. ${ }^{\circ} 91,27-4-1822$.

60 «Sobre el espíritu público», E. C., n. ${ }^{\circ}$ 13, 28-10-1820.
} 
desconocer los gobiernos. La prensa se sitúa así por encima de una mayoría parlamentaria para expresar lo que a su modo de ver es la auténtica mayoría social, sin querer entender, en estos primeros años de experiencia liberal, que la división o la diversidad de intereses va a estar siempre presente en todos los ámbitos de la sociedad y sus órganos de expresión.

\section{EL LABERINTO DE LA IGUALDAD}

Las cautelas para que la libertad no se convierta en el siempre imaginado y temido libertinaje se multiplican al abordar el otro gran concepto del liberalismo, tan ligado también al miedo a los acontecimientos revolucionarios, como es la igualdad.

El Censor, en el número 59, de 15 de septiembre de 1821, se extiende sobre este concepto para aclararlo en todos sus aspectos. Una vez establecido que la libertad natural no existe, por todas las consideraciones enunciadas anteriormente, se concluye que no puede existir tampoco una igualdad natural en derechos, «una proposición destinada únicamente a fascinar al populacho y a erigir en sistema la anarquía». Y así, siguiendo siempre a Bentham, se puede concluir que donde no hay leyes no hay derechos ni seguridad ni propiedad. Pero "¿será cierto que en el estado social son iguales en derechos todos los individuos?». Para resolver esta cuestión, continúa el articulista, hay que hacer una multitud de distinciones. En ningún país civilizado, bajo ninguna constitución, por liberal que la supongamos, son iguales en derechos todos los individuos que habitan ese territorio. Resulta evidente que los extranjeros no tienen los mismos derechos que los naturales, ni los no ciudadanos que los ciudadanos, ni las mujeres los mismos derechos que los hombres, «y en alguna constitución como la nuestra» no tienen plenos derechos «los bancarroteros, los criados domésticos, los que no tengan empleo, oficio o modo de vivir conocido» o los analfabetos.

Resulta, pues, que solo los ciudadanos en ejercicio actual de sus derechos son verdadera y completamente iguales. Sin embargo, cada profesión tiene derechos específicos, como los militares, que tienen derecho a ser hospedados en casas particulares cuando viajan; los eclesiásticos, con derecho a ser mantenidos por el Estado; los jueces, con derecho a mandar prender a los delincuentes, o los legisladores, con derecho a inmunidad parlamentaria. Y aun dentro de cada profesión la desigualdad existe: no tienen los mismos derechos el general y el soldado, el obispo que el párroco, el ministro o el conserje... Entonces ¿en qué sentido los hombres son iguales en derechos? Todos los que están en un determinado país son iguales en aquellos derechos que las leyes 
del país conceden a todos en su territorio, y luego vendrán las diferencias ya expresadas. En resumen, «y si queréis hablar al pueblo el lenguaje de la verdad, y no extraviarle y darle falsas ideas, decidle: todos los individuos de la especie humana que actualmente residen en territorio español tienen igual derecho a que la nación proteja sus personas y propiedades contra la violencia y la expoliación, y a hablar, escribir y publicar por medio de la imprenta cuanto quieran».

Hasta aquí la igualdad/desigualdad legal. Pero hay otra desigualdad que debe ser igualmente respetada: la social, y que obedece a dos principios: el de subordinación o dependencia y el de la opinión o estimación pública. El primero recoge las diferencias entre superior e inferior: el hijo no es igual al padre, el criado al amo, el discípulo al maestro, el trabajador al empleador. El segundo resulta de las circunstancias personales de los individuos: desigualdad de talento, desigualdad de instrucción, desigualdad de nacimiento... Esta última es la más sorprendente en un artículo de difusión de los valores liberales, pero el autor la intenta justificar: esta desigualdad «es la más fútil de todas [...] y aun una injusticia, si se quiere, pero al fin existe». En un gobierno liberal, continúa, no debe haber ninguna desigualdad legal, como la que distingue a nobles y plebeyos, pero «la opinión hará siempre alguna distinción entre el hijo de un ciudadano esclarecido que ha hecho grandes servicios a su patria y el del hombre oscuro». Es una especie de gloria que el padre transmite a sus hijos. Por eso existe la nobleza de opinión que encontramos hasta en las sociedades más republicanas.

Hay también, evidentemente, una desigualdad de riquezas: «Existe de hecho ahora, ha existido antes y existirá siempre mientras haya sociedades que no estén niveladas a la Babeuf, si es que semejante nivelación es posible». Y termina con una "desigualdad de honor entre las profesiones" porque "ciertas operaciones, ciertas habilidades, ciertas artes, son más estimadas que otras y lo que las ejercen más estimados». Y así siempre será mejor considerado el artesano que el saltimbanqui, el arquitecto que el albañil, el abogado, el sabio o el literato que el buhonero, el mozo o el barrendero. Y es también menos honorable el que maneja materias asquerosas o repugnantes, y así el matachín, el carnicero o el zurrador no serán tan honrados como el ebanista o el platero. Y termina con una distinción sorprendente: «Hay ciertas profesiones honradísimas que se degradan por la especie de "mercenariedad" que llevan consigo, como la medicina y la cirujía [sic]. A pesar de su utilidad, dificultad y del grado de instrucción que precisan, no son tan honoríficas como la de militar». ¿Y por qué?: «Porque los facultativos reciben la paga de mano de los enfermos».

Esta exposición pormenorizada de los conceptos de libertad y de igualdad permite captar todo el sentido de la tarea pedagógica que se asigna El Censor. 
Más allá de que la interpretación general de cada uno de ellos estén en consonancia con la del primer liberalismo europeo, como muestra la distinción entre libertad civil y libertad política y la distinción entre igualdad ante la ley y la desigualdad económica, la clave de la vocación educativa está en esas divisiones y subdivisiones que tienen como núcleo el comportamiento social, las jerarquías establecidas, las costumbres, el entramado cotidiano de hábitos y deferencias que deben subsistir por encima de las ideologías y de los regímenes políticos. Para entender hoy, en nuestras sociedades más niveladas, la novedad que pregonaba Tocqueville al hablar de la igualdad de condiciones americana hay que leer este artículo de El Censor y encontrar la auténtica desigualdad de condiciones europea en todo ese conjunto de categorías y subcategorías que sostenían el armazón social, más propio todavía del Antiguo Régimen que de las futuras sociedades liberales. Y aquí se expresa también el miedo a la revolución, más allá de las fuentes de la soberanía o el voto para la elección de representantes. El miedo a una revolución social en la que nuestros hijos nos falten al respeto, las mujeres pretendan ser como sus maridos, los criados se quieran igualar a sus amos y los cirujanos a los militares. De ahí la importancia de instruir al pueblo en cuáles son sus derechos y, sobre todo, en cuáles siguen siendo sus deberes.

\section{PUEBLO Y NACIÓN}

Del resto de los conceptos que aborda la prensa afrancesada para la educación liberal de sus lectores conviene destacar los relacionados con la idea de pueblo y de nación, alrededor de los cuales se agrupan también los de soberanía, autoridad, leyes y representación porque persiguen un objetivo similar al ya descrito para la libertad y la igualdad: conocimiento para poder defenderlos y establecimiento de los límites para evitar abusos.

En primer lugar hay una identificación entre pueblo y nación, no tanto por ignorancia de las diferencias de significado entre ambos vocablos como por la voluntad de que «la respetable voz pueblo no se prostituya a designar la sección menos importante del estado, la menos preparada para designar los comunes intereses». Y así "pueblo es el conjunto de todos los ciudadanos españoles [...]. El pueblo español quiere, delibera, decreta en forma de ley, lo que quieren, deliberan y decretan [...] las cortes españolas» ${ }^{61}$. «En una palabra - dice El Censor - el pueblo es la nación ${ }^{62}$. Y en los países constitucionales

61 «Nación = Pueblo», M. C., n.o. 205, 21-9-1820.

62 «De la autoridad del pueblo en el sistema constitucional», E. C., n.o 10, 7-10-1820. 
el pueblo está en los representantes de su voluntad, y por tanto: "Guardémonos de atribuirle la potestad de deliberar, reunido, sobre las materias que se ventilan en el Congreso. Si estos derechos eran legítimos y fáciles de ejercer en las repúblicas de la antigüedad, no pueden menos de ser usurpación en las monarquías de extenso territorio, donde es imposible que toda la nación se reúna» ${ }^{63}$.

El pueblo-nación es el depositario de la soberanía. Concepto nuevo, de difícil definición, según la Miscelánea ${ }^{64}$, y "cuestión escandalosa para algunos, peligrosa para otros, y según muchos, abstracta e inútil como las fruslerías de los aristotélicos». Pero, en fin, hay que atreverse con él y no queda más remedio que acudir al pacto primigenio, «al poder superior a todos los demás poderes de la sociedad [...], es decir al poder que creó el pacto social o constitución, y nadie duda que este poder primitivo, inajenable, independiente de toda forma de gobierno, reside en la comunidad», luego "la soberanía pertenece a la nación», aun bajo una monarquía absoluta. Pero en los regímenes representativos, una vez constituidos los poderes que la nación juzgó convenientes, «la nación cesó de ser soberana, y quedó súbdita de la autoridad que ella misma estableció». Pero aun hay una potestad superior a la soberanía popular-nacional, la potestad que en las selvas primitivas unió a las familias y convirtió al hombre en un ser moral: la utilidad. La institución universal del gobierno, en su sentido amplio, «prueba que los hombres prefieren desprenderse de una parte de su libertad y de sus derechos, a trueque de obtener orden y libertad $\rangle^{65}$.

Pero no es un trueque zanjado para siempre. El pueblo conserva tres poderes que emanan de su soberanía: el poder electoral, el poder de petición y la libertad de pensamiento. El primero implica que solo se puede estar ligado por las leyes que uno mismo se ha dado y no se puede adulterar con la manipulación de las elecciones o con diputaciones procedentes de las clases privilegiadas. El segundo es la garantía para los ciudadanos particulares, que les permite denunciar los abusos del poder. El tercero, el más importante, está a disposición del pueblo mediante la libertad de imprenta. "La libertad de imprenta coloca en el trono la razón, y esta es, según nuestro entender, la mayor excelencia del sistema representativo» ${ }^{66}$.

63 «De la autoridad del pueblo en el sistema constitucional», E. C., n.o 10, 7-101820.

64 «Sobre la soberanía», M. C., n. ${ }^{\circ} 245,31-10-1820$.

65 Todos estos fragmentos en «De la autoridad del pueblo en el sistema constitucional», E. C., n. ${ }^{\circ}$ 10, 7-10-1820. Para el largo debate entre soberanía del pueblo o soberanía de la nación vid. Morange, C. (2019), pp. 322 y ss.

66 «De la autoridad del pueblo en el sistema constitucional», E. C., n.o 10, 7-10-1820. 
Esta exaltación de la libertad de prensa nos lleva a un último debate muy presente en los inicios del liberalismo y al que la prensa afrancesada dedica varios artículos: la necesidad o no de partidos políticos. El debate se plantea en forma de dicotomía partidos/facciones $\mathrm{y}$, desde luego, no es privativo de España. Es la cuestión que muestra, quizá con mayor nitidez, las dificultades para la consolidación del sistema representativo, para el cambio del Antiguo Régimen a una sociedad políticamente plural. El tema ha sido extensamente tratado por Ignacio Fernández Sarasola en una espléndida monografía ${ }^{67}$ y no necesita mayores precisiones. Sin embargo, debe mencionarse aquí en el conjunto de la tarea de difusión del liberalismo de la prensa afrancesada porque forma parte de esa educación política que debía adquirir el ciudadano, si bien los avances hacia la tolerancia política fueron muy escasos.

Aunque no hay un reconocimiento del derecho de asociación como tal, la defensa de la libertad de pensamiento, que tanto alaba la prensa, nunca implica que esa libertad pueda llevar a distintas maneras de ver un problema y a generar entonces distintos grupos de opinión sobre las cuestiones políticas, siempre dentro del respeto a la Constitución. Hay una confianza ingenua en la razón y en sus dictados para conformar la verdad y una idea unívoca de justicia, y se tiende a denominar partidos o facciones a quienes se considera alejados de esas verdades manifiestas, sobre todo en los primeros meses del Trienio, cuando «los liberales» eran todos los defensores de las libertades y del sistema representativo, y solo eran «partidos» los que formaban los absolutistas. Por eso, y como ya hemos visto, El Censor opone "espíritu de partido" a «espíritu público», siendo el primero el sectario, que «no reconoce más patria que su propia facción, ni otros ciudadanos que los que profesan unas mismas opiniones ${ }^{68}$. Y El Universal ${ }^{69}$ acude muy satisfecho a la opinión del ideólogo Pierre Daunou: «Estoy tan lejos de poner la menor confianza en los manejos y en la agitación de los partidos políticos, que al contrario los tengo por muy perniciosos $\aleph^{70}$.

La Miscelánea, sin embargo, no compartía tal aversión y siempre pretendió dignificar el papel de la oposición política ${ }^{71}$. En su número $130^{72}$

\footnotetext{
Fernández Sarasola (2009).

"Sobre el espíritu público», E.C., n.o 13, 28-10-1820.

69 Diario igualmente afrancesado, pero más cercano al despotismo ilustrado que al liberalismo.

70 «Sobre un partido de oposición», El Universal Observador Español, n. ${ }^{\circ} 36,16-6-$ 1820.

71 López Tábar (2001): 213.

72 «De los partidos y de las facciones», M. C., n.o 130, 8-7-1820.
} 
ofrece un análisis de lo más cercano a una defensa de los partidos políticos que puede encontrarse en la prensa del Trienio. Considera el autor que en todos los Estados libres siempre hay diversidad de opiniones: «Unas son útiles y las otras peligrosas, unas van dirigidas a conservar las leyes y darles vigor, y otras a trastornarlas: he aquí deslindada la diferencia entre los partidos y las facciones». «Los partidos se crean con el fin de sostener intereses comunes y nacionales, y es un síntoma de robustez y de vida en el cuerpo político». "Las facciones están siempre movidas por intereses limitados y por jefes revoltosos. A principios de 1814 había en España un partido y una facción: el partido liberal, que defendía los intereses públicos, y la facción servil, que maquinaba a favor de intereses privados». Y concluye: "Partidos [...] existieron y existirán siempre en todo país donde se quiso y se quiera conservar la libertad». A pesar de que mantiene la línea maniquea ya mencionada de considerar que existe un significado único y manifiesto de lo que es útil y está al servicio de la nación frente a lo que es pernicioso y refleja solo un interés privado, asocia libertad con diversidad de opiniones, aunque sea siempre dentro del marco constitucional.

Conforme avanzaba el Trienio, los cambios ministeriales y la división interna de los liberales pusieron de manifiesto la necesidad de que hubiera al menos dos partidos legítimos: el del Gobierno y el de la oposición, y que la división de opiniones se producía necesariamente en todo gobierno representativo:

No cesaré de aconsejar a todos mis conciudadanos la unión y concordia. Esta no puede verificarse donde no haya tolerancia de opiniones. Mientras no perdamos la costumbre de aborrecer al que disiente de nosotros, no somos verdaderos liberales: mientras insultemos y persigamos, no hemos proscrito la inquisición. Castíguense los delitos: comprímanse los alborotos: pero sean respetadas las opiniones ${ }^{73}$.

Este reconocimiento fue la pérdida definitiva de la pureza ilustrada, de la ilusión de que la razón y la justicia no se imponían por sí mismas haciéndose evidentes a los ojos de los hombres de bien. Se iniciaba un camino mucho más complejo, en el que los ciudadanos podían extraviarse fácilmente.

Sin concesiones al mito de las libertades medievales, sin apego fetichista a la Constitución, en la que no había intervenido, y sin mención alguna ni a la

73 "Apología de la nación española contra las calumnias de los aristócratas franceses», E. C., n.o 88, 6-4-1822. 
religión ni a la Iglesia ${ }^{74}$, la prensa afrancesada difundió un liberalismo en plena correspondencia con las obras teóricas europeas que con frecuencia anunciaba en sus páginas. Tachados, con cierto tono peyorativo, de "doctrinarios» por algunos historiadores ${ }^{75}$, que han juzgado más por los acontecimientos posteriores que por la tarea realizada durante el Trienio, los afrancesados que sostuvieron los periódicos moderados en esos breves años de libertad difundieron más a Bentham y a Constant y a los ideólogos Destutt de Tracy o Cabanis que a Guizot, especialmente en los números de 1820 y 1821, y explicaron con luz favorable los principios claves del liberalismo: soberanía popular, libertad civil y política y división de poderes, si bien advirtiendo siempre de los peligros de una mala interpretación que llevara a la exaltación. En resumen, y esta vez sí de acuerdo con López Tabar $^{76}$, defendieron la vía media de la tolerancia frente al fanatismo y de la moderación frente a cualquier clase de extremismo.

\section{LOS FRUTOS TARDÍOS}

En el breve tiempo que le fue concedido al Trienio se intentó continuar y ampliar el mandato de la Constitución de 1812 de difundir su contenido y de educar a los españoles en principios constitucionales. La tarea de construir una opinión pública, iniciada ya en los años de Cádiz por periódicos como $E l$ Espectador sevillano, se vio ahora alentada con diversas iniciativas.

La temprana traducción de Marcial Antonio López del llamado Curso de politica constitucional, de Benjamin Constant, fue un éxito duradero. El autor ya era bien conocido antes del pronunciamiento de Riego, como lo demuestra que uno de los ejemplares de los Principes de Politique introducidos ilegalmente en Espańa tuviera el honor de ser sometido a un juicio pormenorizado por el Tribunal de la Inquisición restaurado por Fernando VII ${ }^{77}$, que la traducción estuviera lista para la imprenta al poco tiempo de proclamarse de nuevo la Constitución y que los periódicos citaran continuamente sus discursos y tradujeran su conferencia «Sobre la libertad de los antiguos comparada con la de los modernos». Su lectura contribuyó a la formación de liberales como

74 Una excepción por omisión: en el segundo artículo de la traducción de De la libertad de los antiguos comparada con la de los modernos, de Constant, desaparece la frase «sea para profesar el culto que él [individuo] y sus asociados prefieran». Omisión que se debe seguramente a que ha sido tomada de la edición de M. A. López.

75 Los ya mencionados Morange (1990) y López Tabar (2001).

76 López Tabar (2001): 229.

77 Sánchez-Mejía (2013). 
Alcalá Galiano, que justifica en sus Memorias que su liberalismo siempre fue templado porque ya en el Trienio modeló sus ideas con el texto de Constant ${ }^{78}$. Fue elegido para formar parte del Plan de Estudios de Derecho en la Universidad Central, aunque el fin del Trienio impidió su puesta en marcha definitiva. Las Observaciones de López permitieron que el lector comparara los artículos de la Constitución con los principios generales que enunciaba la obra y, al mismo tiempo, marcaron la distancia que todavía separaba al incipiente liberalismo español con el europeo, sobre todo en materia de libertad religiosa, pero también de las atribuciones concedidas a la Corona, dos cuestiones que tardaron casi un siglo en zanjarse.

Como han puesto de manifiesto muchos autores ya citados al principio, la obra de Ramón de Salas marca el inicio de los estudios de derecho constitucional en España. Establece un debate con Bentham, autor del que el propio Salas es el gran difusor en Espańa, pero con el que no siempre coincide, que va a ser muy fructífero durante décadas ${ }^{79}$. El hecho de estar concebida "para las escuelas de España» le otorga una claridad expositiva y unos objetivos didácticos que marcarán toda la trayectoria posterior de la enseñanza de esa materia. Presentado en paralelo con el contenido de la Constitución, pero necesariamente atado a ella como las Observaciones de López, permite una comparación distanciada y constituye una herramienta eficaz para aprender los principios liberales y los mecanismos políticos de los sistemas representativos.

Por último, los diarios afrancesados, junto con el resto de la prensa que no hemos tenido ocasión de comentar aquí, cumplieron esa misión de formación de la opinión, de la que siempre quisieron ser portavoces. Ya se han indicado sus logros y sus temores y, aunque sus artífices nunca lograron el perdón por sus antiguos pecados y acabaron engrosando más bien las filas del absolutismo reformista, es indudable que realizaron una labor de difusión de lo que era en ese momento el liberalismo europeo de manera más independiente que otros diarios, ligados a grupos e intereses políticos más concretos.

El Trienio fue, en definitiva, un importante periodo, pese a su corta duración, para familiarizar a los espańoles con conceptos y mecanismos que sería necesario ir afilando a lo largo del siglo.

78 Alcalá Galiano (1955). Aunque el autor especifica que leyó a Constant «en su original francés", p. 81.

79 Sánchez García (2007). 


\section{BIBLIOGRAFÍA}

Alcalá Galiano, A. (1955). Memorias. Madrid: B. A. E.

Álvarez Alonso, C. (2000). Un rey, una ley, una religión (goticismo y constitución histórica en el debate constitucional gaditano). Revista de Historia Constitucional, 1, 1-62. Disponible en: https://doi.org/10.17811/hc.v0i1.106.

Baltar Rodríguez, J. F. (2011). Destierro y exilio de un académico de la Historia: D. Marcial Antonio López Quílez, Barón de La Joyosa. En J. Alvarado Planas (coord.). Estudios sobre historia de la intolerancia (pp. 563-572). Madrid: Mesina.

Bermejo Cabrero, J. L. (1982). Introducción. En R. Salas Lecciones de derecho político constitucional. Madrid: Centro de Estudios Constitucionales.

- (s. f.). Ramón de Salas y Cortes. Diccionario biográfico de la Real Academia de Historia. Disponible en: https://bit.ly/2LU9mPP.

Bustos, S. (2015). Contribución al debate sobre las dos interpretaciones de la Constitución de Cádiz en el Trienio Liberal (1820-1823). En J. A. Caballero López, J. M. Delgado Idarreta y R. Viguera Ruiz (coords.). El lenguaje político y retórico de las constituciones españolas: Proyectos ideológicos e impacto mediático en el siglo XIX (pp. 59-74). Oviedo: Servicio de Publicaciones de la Universidad de Oviedo.

Carbajosa Aguilera, M. (2016). Alberto Lista y el origen del gobierno representativo. Revista Internacional de Pensamiento Politico, 11, 191-211.

Constant, B. (1818) Collection complète des ouvrages publiés sur le Gouvernement représentatif et la Constitution actuelle de la France, formant une espèce de Cours de politique constitutionnelle. Paris: Plancher.

- (1820). Curso de política constitucional, traducido libremente al español por Marcial Antonio López. Madrid: Imprenta de la Compañía.

Fernández Alles, J. J. (2012). La enseñanza de la constitución tras las Cortes de Cádiz: particular referencia al manual de Ramón Salas y a las cátedras de constitución. En G. Butrón Prida (comp.). Las Españas y las Américas: los españoles de ambos hemisferios ante la crisis de independencia (pp. 303-314). Cádiz: Universidad de Cádiz, Servicio de Publicaciones.

Fernández Sarasola, I. (2009). Los partidos politicos en el pensamiento español. De la Ilustración a nuestros días. Madrid: Marcial Pons Historia.

- (2011). Ramón de Salas y la nueva ciencia jurídica. Teoría y Realidad Constitucional, 28, 633-648. Disponible en: https://doi.org/10.5944/trc.28.2011.6976.

García Costa, F. M. (2005). Las Lecciones de Ramón de Salas y los orígenes de la ciencia española del derecho constitucional. Empresas politicas, 6, 35-48.

González Manso, A. I. (2011). Los principios políticos de Alberto Lista: un análisis conceptual e histórico. Revista de Estudios Políticos, 152, 143-181.

Juretschke, H. (1951). Vida, obra y pensamiento de Alberto Lista. Madrid: CSIC.

La Parra López, E. (2014), Intransigencia y tolerancia religiosa en el primer liberalismo español. La tolerancia religiosa en la España contemporánea. Mélanges de la Casa de Velázquez, 44 (1), 45-63. Disponible en: https://doi.org/10.4000/mcv.5486. 
Llorente Sariñena, M. (2006). Ámbitos constitucionales e historiografía de la constitución: la nación doceañista. En J. Álvarez Junco y J. Moreno Luzón (coords.) La Constitución de Cádiz: historiografía y conmemoración: homenaje a Francisco Tomás y Valiente (pp. 143-152) Madrid: Centro de Estudios Políticos y Constitucionales.

López Tabar, J. (2001). Los famosos traidores. Los afrancesados durante la crisis del Antiguo Régimen (1808-1833). Madrid: Biblioteca Nueva.

Morán Ortí, M. (1989). La Miscelánea de Javier de Burgos: la prensa en el debate ideológico del Trienio Liberal. Hispania Sacra, 41 (83), 237-334.

Morange C. (1990). Siete calas en la crisis del Antiguo Régimen español. Alicante: Diputación de Alicante.

(2004). Opinion publique: ambivalence d'un concept (Espagne, 1750-1823). En J. Fernández Sebastián y J. Chassin (coords.). L'avènement de l'opinion publique. Europe et Amérique XVIIIè-XIXè siècles (pp. 181-210). Paris: L'Hartmattan.

— (2019). Los orígenes del moderantismo decimonónico. «El Censor» (1820-1822): promotores, doctrina e indice. Salamanca: Ediciones de la Universidad de Salamanca.

Peset, M. y García Trobat, P. (1998). Las primeras cátedras de constitución. Cuadernos del Instituto Antonio de Nebrija de estudios sobre la Universidad, 1, 225-244.

Salas, R. (1982). Lecciones de derecho político constitucional. Madrid: Centro de Estudios Constitucionales.

Sánchez Agesta, L. (1962). Las primeras cátedras de Derecho Constitucional. Revista de Estudios Políticos, 126, 157-167.

Sánchez de la Campa, J. M. (1871). Historia filosófica de la instrucción pública en España. Burgos: s. e.

Sánchez García, R. (2007). Lecturas de Bentham en España (1820-1823). En M. C. García Tejera (coord.) Lecturas del pensamiento filosófico, politico y estético. Actas XIII Encuentro de la Ilustración al Romanticismo (1750-1850) (pp. 117-128). Cádiz: Ediciones de la Universidad de Cádiz.

Sánchez-Mejía, M. L. (1998) Benjamin Constant en España, 1820-1825. Boletín de la Institución Libre de Enseñanza, 32-33, 109-121.

- (2013) La Inquisición contra el liberalismo. El expediente de calificación de los Principes de Politique de Benjamin Constant. Cuadernos Dieciochistas, 14, 283-303.

— (s. f.). Marcial Antonio Lopez Quílez. Diccionario biográfico de la Real Academia de Historia. Disponible en: https://bit.ly/3qqkQts.

Varela Suanzes, J. (1998) El debate sobre el sistema británico de gobierno en España durante el primer tercio del siglo xix. En J. M. Ińurritegui y J. M. Portillo (eds.). Constitución en España: orígenes y destinos (pp. 79-108). Madrid: Centro de Estudios Políticos y Constitucionales.

Torrecilla, J. (2016). España al revés. Los mitos del pensamiento progresista. Madrid: Marcial Pons Historia. Disponible en: https://doi.org/10.2307/j.ctt20fw6vg. 